\title{
The Effect of Video Tutorials on Learning Spreadsheets
}

\author{
Ayşe Begüm Aydinol \\ Department of Computer and Instructional Technology \\ Teacher Education Bilkent University \\ ANKARA/TURKEY \\ +905396602979 \\ aydinol@ug.bilkent.edu.tr
}

\begin{abstract}
In this study a video tutorial for spreadsheet use (Excel) will be prepared by two undergraduate students by using a recorder and applied on a group of students to understand how effective this kind of a tutorial is to increase student achievement.
\end{abstract}

\section{Categories and Subject Descriptors}

K.3.1 [Computers and Education]: Computer Uses in Education - Computer-assisted instruction (CAI).

\section{General Terms}

Performance, Measurement.

\section{Keywords}

Computer-assisted instruction, video tutorial, student achievement, instructional technology, independent learning, spreadsheet (Excel).

\section{INTRODUCTION}

This study is prepared by two undergraduate students of Computer and Instructional Technology Teacher Education Department to analyze how computer-assisted instruction can effect the student achievement and help instructor during the lesson.

\subsection{Purpose of the Study}

The purpose of the study is to present a helpful tool for the students who study spreadsheet use (Excel), and encourage the use of computers. The usability of the prepared tool will be measured by the computer-assisted instruction of the instructor and this tool will be used by the students.

This study will be conducted in Bilkent University at 2009-2010 spring semester, at an introductory ICT skills lesson for freshmen students from the departments of Computer and Instructional Technology Teacher Education and/or Management. The study will give valuable information about the effects of the prepared tutorial on the success and interest of the students so that this kind of tutorials may be used as an aid in courses more frequently.

\subsection{Problem Statement}

During the teaching process of an application, generally students ask questions about what the instructor explains and shows.

Some students may try to take notes while the instructor shows how to use the application and do certain things.

Copyright is held by the author/owner(s).

ITiCSE'10, June 26-30, 2010, Bilkent, Ankara, Turkey.

ACM 978-1-60558-820-9/10/06.

\author{
Özgür Gültekin \\ Department of Computer and Instructional Technology \\ Teacher Education Bilkent University \\ ANKARA/TURKEY \\ $+905359672416$ \\ o_gultekin@ug.bilkent.edu.tr
}

In this process, it is hard to take notes for the students while applying the information by themselves. Also, it is difficult for the instructor to pay attention to each student individually. To overcome such problems, a video tutorial can be used to show the functions of the application taught so that the students will not have the difficulty to take notes since the necessary explanations are already in the tutorial which helps them to remember and revise any time they want. In brief, in the study to what extent a video tutorial is helpful for the students to increase their achievement will be examined.

\subsection{Significance of the Study}

When the students deal with taking notes about the instructor's explanations, they often miss some parts and also cannot pay attention to the whole action of the instructor. Hence, when it comes to hands-on practice, the students may not perform the intended task since they do not comprehend the essence. Besides, the instructor may not be able to answer all of the questions that the students ask since there is limited time for the lesson.

Instead of having these kinds of problems during the lesson which decrease the motivation and focus of the students, having a tutorial which covers the necessary examples both visually and auditory can be quite helpful for the students and it will encourage independent learning as well.

\section{METHODOLOGY}

The study will be conducted at Bilkent University and the participants will be a group of Bilkent University students who take an introductory ICT skills lesson. The participants will be chosen by convenience sampling since the available and volunteer students will participate in this study. There will be an organized video tutorial for spreadsheet use which will be prepared by screen casting. This video tutorial will be different than just showing screenshots since the tutorial shows the usage of the application in motion. The students will be able to see the movements of the mouse while hearing the voice of the speaker. This tutorial will be used for helping students in the learning process as well as helping the instructor to improve delivery of instruction.

\section{CONCLUSION}

To spend the lesson time more efficiently while letting the students internalize the information, the computer aids can be used to increase the student achievement by providing an easier way for understanding which encourages self-regulated learning.

We hope that the findings of the study will be helpful for both instructors and students. 